\title{
Comparing outcomes of hospitalized patients with moderate and severe COVID-19 following treatment with hydroxychloroquine plus atazanavir/ritonavir
}

\author{
Hamid Rahmani ${ }^{1}$ - Effat Davoudi-Monfared ${ }^{1} \cdot$ Anahid Nourian $^{1} \cdot$ Morteza Nabiee $^{1} \cdot$ Setayesh Sadeghi $^{1}$. \\ Hossein Khalili ${ }^{1}$ (D) - Ladan Abbasian ${ }^{2} \cdot$ Fereshteh Ghiasvand $^{2} \cdot$ Arash Seifi $^{2} \cdot$ Malihe Hasannezhad $^{2}$. \\ Sara Ghaderkhani ${ }^{2} \cdot$ Mostafa Mohammadi $^{3}$ - Mir Saeed Yekaninejad ${ }^{4}$
}

Received: 4 July 2020 / Accepted: 11 August 2020 / Published online: 28 August 2020

(C) Springer Nature Switzerland AG 2020

\begin{abstract}
Background The role of the antiviral therapy in treatment of COVID-19 is still a matter to be investigated. Also efficacy and safety of antiviral regimens were not compared according severity of the disease. In this study the efficacy and safety of hydroxychloroquine plus atazanavir/ritonavir was compared in patients with moderate and severe COVID-19.

Methods We prospectively evaluated the clinical outcomes of 213 patients with COVID-19 during the hospitalization course and up to 56 days after the hospital discharge. The disease was categorized to moderate and severe based on the severity of pneumonia and peripheral oxygen saturation $(\mathrm{SpO} 2)$. The patients received the national treatment protocol containing hydroxychloroquine (400 mg BD in first day and then $200 \mathrm{mg}$ BD) plus atazanavir/ritonavir (300/100 mg daily) for 7 days. Main outcomes included discharge rates at day 7, 14 and 28, 28-day mortality, rate of intensive care unit (ICU) admission and intubation, length of hospital and ICU stay and incidence of adverse events.

Results The mean (SD) age of patients was 60(14) years and 53\% were male. According to WHO definition, $51.64 \%$ and $48.36 \%$ of the patients had moderate $(\mathrm{SpO} 2 \geq 90 \%)$ and severe disease $(\mathrm{SpO} 2<90 \%)$ at baseline, respectively. The discharge rate of the moderate group was significantly higher than the severe group at day 7,14 and 28 ( $\mathrm{HR}=0.49 ; 95 \% \mathrm{CI}: 0.35-0.69$, p $=<0.001$ at day $7, \mathrm{HR}=0.48 ; 95 \% \mathrm{CI}: 0.35-0.66, \mathrm{p}=<0.001$ at day 14 and $\mathrm{HR}=0.49$; 95\% CI: $0.36-0.67, \mathrm{p}=<0.001$ at day 28). The 28day mortality of the severe group was six times higher than the moderate group (HR=6.00; 95\% CI: $2.50-14.44)$, p $=<0.001)$.
\end{abstract}

Hossein Khalili

khalilih@tums.ac.ir; Khalilih@sina.tums.ac.ir

Hamid Rahmani

hmdrahmani89@gmail.com

Effat Davoudi-Monfared

edavudimonfared@gmail.com

Anahid Nourian

anahid.nourian@gmail.com

Morteza Nabiee

m1450nabiee@gmail.com

Setayesh Sadeghi

sadeghi.setayesh@gmail.com

Ladan Abbasian

la.abbasian@gmail.com

Fereshteh Ghiasvand

ghiasvand_62@yahoo.com

Arash Seifi

dr.seifi@gmail.com
Malihe Hasannezhad

malihehasannezhad@yahoo.com

Sara Ghaderkhani

sghaderkhani@gmail.com

Mostafa Mohammadi

mohammady_mm@tums.ac.ir

Mir Saeed Yekaninejad

yekaninejad@yahoo.com

1 Department of Pharmacotherapy, Imam Khomeini Hospital Complex, Tehran University of Medical Sciences, Tehran, Iran

2 Department of Infectious Diseases, Imam Khomeini Hospital Complex, Tehran University of Medical Sciences, Tehran, Iran

3 Department of Intensive Care Unit, Imam Khomeini Hospital Complex, Faculty of Medicine, Tehran University of Medical Sciences, Tehran, Iran

4 Department of Epidemiology and Biostatistics, School of Public health, Tehran University of Medical Sciences, Tehran, Iran 
The need of admission in ICU for the severe group and the moderate group was $37.86 \%$ and $18.18 \%$ of the patients. Length of hospital stay was significantly shorter in the moderate group in comparison with the severe group ( $5 \pm 4$ vs. $8 \pm 6$ days, $p<0.001)$. Patients in the moderate group experienced the serious adverse events and complications less than the severe group. The discharged patients were followed up to 56 days after discharge. Some of the patients complained of symptoms such as exertional dyspnea, weakness and new-onset hair loss.

Conclusion Our study did not support the use of hydroxychloroquine plus atazanavir/ritonavir in patients who had $\mathrm{SpO}_{2}<90 \%$ at the time of hospital admission. SpO2 was the only predictor of clinical outcomes (duration of hospital stay, discharge from the hospital and mortality) in patients treated with hydroxychloroquine plus atazanavir/ritonavir.

Keywords COVID- $19 \cdot$ Hydroxychloroquine $\cdot$ Atazanavir/ritonavir $\cdot$ Outcomes

\section{Introduction}

Severe acute respiratory syndrome coronavirus 2 (SARS$\mathrm{CoV}-2$ ), the emerged life threatening coronavirus, has been known as a serious concern worldwide. It received attention when a series of 'unknown viral pneumonia' in China's Hubei province in late December, 2019 were identified [1]. The century witnesses its third corona virus outbreak i.e. COVID-19 (Coronavirus Disease 2019) after SARS (Severe Acute Respiratory Syndrome) in 2003 and MERS (Middle East Respiratory Syndrome) in 2012 [2]. Although many attempts have been made to slow the spread of infection, the World Health Organization (WHO) declared it as a pandemic on 11th March, 2020 [3]. The virus has now infected more than fifteen million people around the world [4].

Like the other outbreaks of coronavirus, the definite treatment of COVID-19 is yet to be known [5]. Supportive cares and the respiratory supports are the recommended resuscitative interventions now. The role of the antiviral therapy in treatment of COVID-19 is still a matter to be investigated. Also efficacy and safety of antiviral regimens were not compared according severity of the disease. In this study the efficacy and safety of hydroxychloroquine plus atazanavir/ritonavir were compared in patients with moderate and severe COVID-19.

\section{Materials and methods}

\section{Study design and participants}

Patients with moderate and severe COVID-19 who were admitted to Imam Khomeini Hospital Complex during 20 February to 29 March 2020 were enrolled in this prospective cohort study. The hospital is one of the major hospitals for admission and care of patients with COVID-19 in Tehran, capital of Iran. According to the national committee of COVID-19, the admission indications were the presence of one or more of the subsequent conditions: (1) peripheral oxygen saturation $(\mathrm{SpO} 2)$ less than $93 \%$ in ambient air (2) respiratory rate more than 30 breath per minute (3) lung infiltration highly suspicious for COVID-19 in chest imaging. Discharge criteria included all of the following: (1) improvement in clinical signs and symptoms based on decision making of physician (2) afebrile status for $72 \mathrm{~h}$ without antipyretics (3) $\mathrm{SpO} 2$ more than $93 \%$ in ambient air without supplemental oxygen.

According to the disease severity and WHO definitions [6], the patients were categorized to moderate or severe group. Patients in the moderate group had primary symptoms of pneumonia (dyspnea, cough and fever) and $\mathrm{SpO} 2 \geq 90 \%$ in ambient air and patients in the severe group had profound pneumonia and $\mathrm{SpO} 2<90 \%$.

The sampling for diagnosis of infection was performed according to the WHO interim guidance [7]. The diagnosis was according to positive reverse transcriptase- polymerase chain reaction (RT-PCR) of nasopharyngeal secretions (197 patients) or clinical data plus chest CT scan findings that were highly suggestive for COVID-19 (16 patients).

Ethics Committee of Tehran University of Medical Sciences approved the study (approval ID: IR.TUMS.VCR.REC.1398.1058). Written informed consents were obtained from the patients or one of the first-degree family members if patient was unconscious. The study protocol was also registered as IRCT20100228003449N30.

\section{Procedures}

Hydroxychloroquine (Modaquenil ${ }^{\circledR}$, Mofid Pharmaceutical co., Iran) as $400 \mathrm{mg} \mathrm{BD}$ in first day and then $200 \mathrm{mg}$ BD plus atazanavir/ritonavir (ATAZOR-R, Emcure Pharmaceutical co., India) as 300/100 mg daily were started within $24 \mathrm{~h}$ of the hospital admission for all patients. The duration of treatment was 7 days. Patients completed the duration of treatment at home if they were discharged before fulfillment of treatment in hospital. Other treatments that were considered for patients such as other antivirals, corticosteroids, intravenous immunogluboline (IVIG), vitamin C, antibiotics, analgesic agents, anti-nausea/vomiting agents, cardiovascular drugs, 
deep vein thrombosis and stress ulcer prophylaxis were recorded.

\section{Data collection}

Demographic, clinical presentations of the diseases, baseline diseases, drug history, laboratory and medical data were collected. The patients' symptoms such as fever, cough, dyspnea, myalgia, arthralgia, gastrointestinal (GI) complaints and sings including $\mathrm{SpO} 2$, pulse rate, respiratory rate, blood pressure and temperature were recorded at the time of hospital admission. Laboratory tests such as white blood cells, serum electrolytes, liver and kidney enzymes and inflammatory biomarkers consisting $\mathrm{C}$ - reactive protein (CRP) and Erythrocyte Sedimentation Rate (ESR) were extracted from the Hospital Information System (HIS).

\section{Definitions}

ARDS was defined based on the Berlin criteria and the risk was stratified according to the $\mathrm{SpO} 2 / \mathrm{FiO}_{2}$ ratio [8]. Acute kidney injury (AKI) was defined according to the Kidney Disease Improving Global Outcomes (KDIGO) criteria [9]. Acute hepatic injury (AHI) was considered when hepatic aminotransferases serum levels raised more than three times the upper limit of normal or serum total bilirubin above $2 \mathrm{mg} / \mathrm{dl}$ [10]. Acute cardiac injury (ACI) was described as troponin serum level above the 99th-percentile the upper limit normal, regardless of presence or absence of the abnormal findings in echocardiography or electrocardiography [11].

\section{Outcomes}

Efficacy outcomes were defined as discharge rate at days 7, 14 and 28, 28-day mortality, rate of intensive care unit (ICU) admission and intubation, length of hospital and ICU stay. Complications during hospitalization such as GI problems, ARDS, AKI, AHI and ACI were considered as safety outcomes.

\section{Follow up}

Discharged patients were followed at days 28 and 56 by phone call. Time to the functional recovery, complications, readmission and death were assessed at those times.

\section{Statistical analysis}

All statistical analysis was performed using SPSS version 21.0. The continuous variables were presented as mean \pm standard deviation, median and interquartile range (IQR) and categorical variables were described as number and frequency rate (percentage). If the distribution of data was normal (pass the normality test), independent samples t-test was applied to compare the continuous variables, otherwise Mann-Whitney $\mathrm{U}$ test was used. Categorical variables were compared by Chisquare test. The Hazard Ratio (HR) and 95\% CI for discharge and mortality rates were calculated by Cox proportional hazards regression analysis. Effects of demographic variables (age and body mass index), comorbid conditions (ischemic heart disease and hypertension), laboratory parameters (CRP) and treatment modalities (corticosteroids, IVIG, vitamin C, ACEI, ARB) on mortality were assessed by adjusted Cox proportional hazards regression models as confounding factors. Finally, Kaplan-Meier cumulative survival plot was created.

\section{Results}

\section{Participants}

During the study period, $110(51.64 \%)$ and 103(48.36\%) patients with moderate and severe disease were included respectively. Mean age \pm SD of patients was $60 \pm 14$ years and number of males was slightly more than females (113 vs. 100). The most common baseline diseases among the patients were hypertension (39.90\%), diabetes mellitus (32.86\%), cardiovascular diseases other than hypertension $(28.63 \%)$ and hypothyroidism $(10.79 \%)$. The most frequent symptoms were dyspnea (61.97\%), cough $(59.62 \%)$ and fever $(58.21 \%)$ as presented. Patients in severe group were older than the moderate group (61 \pm 12 vs. $58 \pm 15$ years, $p=0.085$ ). Baseline characteristics, baseline diseases (except ischemic heart disease) and drug history were not different between the groups (Table 1).

Vital signs and laboratory data of the patients were compared between the groups (Table 2).

All admitted patients required a type of the respiratory supports including nasal cannula, face mask, non-invasive positive pressure ventilation (NIPPV) and invasive mechanical ventilation (IMV). Ribavirin, interferon, Azithromycin, corticosteroid, IVIG, or vitamin C were considered for patients according the experts' opinions. A corticosteroid was administered in $10.0 \%$ and $23.30 \%$ of patients in the moderate and severe groups respectively $(p=0.01)$. Also, $12.62 \%$ of patients in the severe group and $4.54 \%$ of patients in the moderate group received IVIG $(p=0.047)$. Intravenous vitamin $\mathrm{C}$ was administrated for $27 \%$ and $9.09 \%$ of patients in the severe and moderate groups respectively $(p=0.001)$. Patients in the severe group received more antibiotics than in the moderate group $(60.19 \%$ vs. $32.72 \%, p<0.001)$. Other findings are summarized in Table 3. 
Table 1 Baseline characteristics of patients

\begin{tabular}{|c|c|c|c|}
\hline Characteristic & $\begin{array}{l}\text { Patients with } \\
\text { moderate disease } \\
(N=110)\end{array}$ & $\begin{array}{l}\text { Patients with } \\
\text { severe disease } \\
(N=103)\end{array}$ & $\begin{array}{l}p \\
\text { value }\end{array}$ \\
\hline Age (year), mean $\pm \mathrm{SD}$ & $58 \pm 15$ & $61 \pm 12$ & 0.085 \\
\hline Male sex, $\mathrm{n}(\%)$ & $63(57.27)$ & $50(48.54)$ & 0.218 \\
\hline Female sex, $\mathrm{n}(\%)$ & $47(42.73)$ & $53(51.46)$ & \\
\hline $\mathrm{BMI}\left(\mathrm{Kg} / \mathrm{m}^{2}\right)$, mean $\pm \mathrm{SD}$ & $26 \pm 4$ & $27 \pm 4$ & 0.121 \\
\hline \multicolumn{4}{|l|}{ Baseline diseases, n (\%) } \\
\hline Hypertension & $38(34.54)$ & $47(45.63)$ & 0.123 \\
\hline Diabetes mellitus & $33(30)$ & $37(35.92)$ & 0.384 \\
\hline Ischemic heart disease & $22(20)$ & $39(37.86)$ & 0.006 \\
\hline Hypothyroidism & $13(11.81)$ & $10(9.70)$ & 0.664 \\
\hline Malignancy & $8(7.27)$ & $4(3.88)$ & 0.377 \\
\hline $\begin{array}{l}\text { Neuropsychiatric } \\
\text { disorders }\end{array}$ & $5(4.54)$ & $8(7.76)$ & 0.397 \\
\hline Renal disease & $3(2.72)$ & $6(5.82)$ & 0.320 \\
\hline Rheumatoid Arthritis & $4(3.63)$ & $3(2.91)$ & 1.00 \\
\hline $\begin{array}{l}\text { Other rheumatologic } \\
\text { disease }\end{array}$ & $3(2.72)$ & $3(2.91)$ & 1.00 \\
\hline Asthma & $2(1.81)$ & $1(0.97)$ & 1.00 \\
\hline Transplantation & $2(1.81)$ & $1(0.97)$ & 1.00 \\
\hline COPD & $1(0.90)$ & $2(1.94)$ & 0.611 \\
\hline Liver disease & 0 & $2(1.94)$ & 0.233 \\
\hline \multicolumn{4}{|l|}{ History of drugs, $\mathrm{n}(\%)$} \\
\hline $\mathrm{ARB}$ & $31(28.18)$ & $32(31.06)$ & 0.655 \\
\hline Metformin & 19(17.27) & $28(27.18)$ & 0.099 \\
\hline Aspirin & $18(16.36)$ & $27(26.21)$ & 0.094 \\
\hline Beta-blockers & $14(12.72)$ & $21(20.38)$ & 0.143 \\
\hline Insulin & $11(10)$ & $11(10.67)$ & 1.00 \\
\hline Corticosteroids & $8(7.27)$ & $5(4.85)$ & 0.572 \\
\hline Hydroxychoroquine & $7(6.36)$ & $10(9.70)$ & 0.451 \\
\hline Immunosuppressants & $5(4.54)$ & $3(2.91)$ & 0.723 \\
\hline NSAIDs & $4(3.63)$ & $1(0.97)$ & 0.370 \\
\hline Methotrexate & $4(3.63)$ & $1(0.97)$ & 0.370 \\
\hline ACEI & $3(2.72)$ & $6(5.82)$ & 0.320 \\
\hline Azathioprine & $1(0.90)$ & 0 & 1.00 \\
\hline Sulfasalazine & 0 & $2(1.94)$ & \\
\hline \multicolumn{4}{|c|}{ Symptoms at the time of hospital admission, $\mathrm{n}(\%)$} \\
\hline Dyspnea & $66(60)$ & $66(64.07)$ & 0.574 \\
\hline Cough & $63(57.27)$ & $64(62.13)$ & 0.488 \\
\hline Fever & $62(56.36)$ & $62(60.19)$ & 0.581 \\
\hline Chills & $38(34.54)$ & $33(32.03)$ & 0.772 \\
\hline Myalgia & $38(34.54)$ & $44(42.71)$ & 0.260 \\
\hline Malaise & $24(21.81)$ & $31(30.09)$ & 0.210 \\
\hline Nausea & $22(20)$ & $18(17.47)$ & 0.726 \\
\hline Vomiting & $19(17.27)$ & $18(17.47)$ & 1.00 \\
\hline Anorexia & $15(13.63)$ & $16(15.53)$ & 0.703 \\
\hline Chest discomfort & $12(10.90)$ & $8(7.76)$ & 0.487 \\
\hline Diarrhea & $10(9.09)$ & $6(5.82)$ & 0.441 \\
\hline Headache & $8(7.27)$ & 11(10.67) & 0.473 \\
\hline Sore throat & $8(7.27)$ & $2(1.94)$ & 0.103 \\
\hline Abdominal pain & $7(6.36)$ & $5(4.85)$ & 0.769 \\
\hline Anosmia & $1(0.90)$ & 0 & 1.00 \\
\hline $\begin{array}{l}\text { Days of symptoms before } \\
\text { the hospital admission, } \\
\text { median (IQR) }\end{array}$ & $7(4-10)$ & $7(4-10)$ & 1.00 \\
\hline
\end{tabular}

COPD: chronic obstructive pulmonary disease, ARB: Angiotensin $\Pi$ Receptor Blocker, ACEI: angiotensin converting enzyme inhibitor, NSAID: non-steroidal anti-inflammatory drug

\section{Outcomes}

In the moderate group, $77.27 \%$ of patients were discharged at day 7 while this value was $49.51 \%$ in the severe group (HR =
0.49; $95 \%$ CI: $0.35-0.69, \mathrm{p}=<0.001)$. Furthermore, discharge rates were significantly higher in the moderate group compared with the severe group at days 14 and $28(\mathrm{HR}=0.48$; 95\% CI: $0.35-0.66, \mathrm{p}=<0.001$ at day 14 and $\mathrm{HR}=0.49 ; 95 \%$ CI: $0.36-0.67, \mathrm{p}=<0.001$ at day 28$)$. The 28-day mortality rate was much higher in the severe group in comparison with the moderate group (HR $=6.00 ; 95 \% \mathrm{CI}: 2.50-14.44), \mathrm{p}=<$ 0.001) (Fig. 1). Out of patients in the moderate and severe groups, $18.18 \%$ and $37.86 \%$ were admitted to ICU respectively $(p=0.002)$. Of these patients, $40 \%$ and $74.35 \%$ were intubated in the moderate and severe groups respectively. Average ICU length of stay was not significantly different between the groups. However, mean \pm SD of hospital stay was statistically longer in the severe group than moderate group ( $8 \pm 6$ vs. $5 \pm 4$ days, $p<0.001$ ). Nausea, vomiting, dyspepsia, abdominal pain, diarrhea were GI complaints in $16.90 \%$ of patients. During the hospitalization course, 47 $(45.63 \%)$ and $8(7.27 \%)$ of patients in the severe and moderate groups experienced ARDS respectively. Prevalence of AKI was significantly higher in the severe group than moderate group ( $24.27 \%$ vs. $7.27 \%$ respectively, $p=0.001)$. Incidence of AHI $(15.53 \%$ vs. $5.45 \%, p=0.023)$ was significantly higher in the severe than moderate groups. The incidence of ACI was not statistically different between the groups $(22.33 \%$ vs. $16.35 \%, p=0.300)$ (Table 4$)$.

\section{Adjusted cox proportional regression models}

To evaluate the effect of confounding factors on mortality rate, Cox regression models were adjusted for these variables. However, significant deference in mortality rate was detected between the groups $(\mathrm{HR}=3.89 ; 95 \% \mathrm{CI}: 1.36-11.11, p=$ 0.011).

\section{8-day and 56-day follow up}

Of 176 discharged patients, 3 patients died at day 28. Other 173 patients were alive on day 56 . Readmission rates were $3.97 \%$ and $1.70 \%$ at days 28 and 56 respectively. The median (IQR) time to functional recovery was $7(0-14)$ days. At day 56,3 and 6 patients reported significant hair loss and exertional dyspnea respectively. Moreover, four patients complained about generalized weakness and dizziness. Up to June 10 , $2020,173 / 213(81.22 \%)$ patients were alive.

\section{Discussion}

To the best of our knowledge, for the first time, outcomes of hospitalized patients with moderate and severe COVID-19 treated with hydroxychloroquine plus atazanavir/ritonavir, were compared. 
Table 2 Vital signs and laboratory data

\begin{tabular}{|c|c|c|c|}
\hline Vital sign & $\begin{array}{l}\text { Mean } \pm \text { SD } \\
\text { in patients with moderate disease }\end{array}$ & $\begin{array}{l}\text { Mean } \pm \text { SD } \\
\text { in patients with severe disease }\end{array}$ & $\mathrm{p}$ value \\
\hline Temperature $\left({ }^{\circ} \mathrm{C}\right)$ & $37.87 \pm 0.84$ & $37.87 \pm 0.84$ & 0.989 \\
\hline Heart rate (beats /minute) & $91 \pm 14$ & $91 \pm 15$ & 0.973 \\
\hline Respiratory rate (breaths /minute) & $21 \pm 4$ & $21 \pm 4$ & 0.478 \\
\hline Systolic blood pressure (mm Hg) & $124 \pm 19$ & $121 \pm 16$ & 0.265 \\
\hline \multicolumn{4}{|l|}{ Laboratory data } \\
\hline White Blood Cell (cells $/ \mu 1)$ & $7090 \pm 3887$ & $7063 \pm 3904$ & 0.960 \\
\hline Acute Lymphocyte count (cells / $\mu$ l) & $1086 \pm 480$ & $1133 \pm 1049$ & 0.677 \\
\hline $\operatorname{Hemoglobin}(\mathrm{g} / \mathrm{dl})$ & $13.07 \pm 2.33$ & $13.46 \pm 2.01$ & 0.204 \\
\hline Platelet count (cells $\left.\times 10^{3} / \mu \mathrm{l}\right)$ & $205 \pm 74$ & $199 \pm 73$ & 0.598 \\
\hline Blood Urea Nitrogen (mg/dl) & $17 \pm 13$ & $19 \pm 12$ & 0.293 \\
\hline Creatinine $(\mathrm{mg} / \mathrm{dl})$ & $1.30 \pm 0.78$ & $1.14 \pm 0.42$ & 0.082 \\
\hline Aspartate aminotransferase $(\mathrm{u} / \mathrm{l})$ & $44 \pm 29$ & $45 \pm 32$ & 0.900 \\
\hline Alanine aminotransferase $(\mathrm{u} / \mathrm{l})$ & $38 \pm 27$ & $36 \pm 20$ & 0.524 \\
\hline Alkaline phosphatase $(\mathrm{u} / \mathrm{l})$ & $197 \pm 122$ & $175 \pm 77$ & 0.207 \\
\hline Total bilirubin(mg/dl) & $0.74 \pm 0.50$ & $0.89 \pm 0.77$ & 0.180 \\
\hline C-reactive protein(mg/dl) & $94 \pm 78$ & $117 \pm 75$ & 0.053 \\
\hline Erythrocyte sedimentation rate $(\mathrm{mm} / \mathrm{h})$ & $65 \pm 32$ & $66 \pm 27$ & 0.823 \\
\hline
\end{tabular}

Table 3 Respiratory support and medications

\begin{tabular}{|c|c|c|c|}
\hline Parameter & Patients with moderate disease $(\mathrm{N}=110)$ & Patients with severe disease $(\mathrm{N}=103)$ & $\mathrm{p}$ value \\
\hline \multicolumn{4}{|l|}{ Respiratory support, n (\%) } \\
\hline Nasal cannula & $20(18.18)$ & $11(10.67)$ & \multirow[t]{3}{*}{0.001} \\
\hline Face mask & $82(74.54)$ & $63(61.16)$ & \\
\hline IMV & $8(7.27)$ & $29(28.15)$ & \\
\hline \multicolumn{4}{|c|}{ Applied medications during hospitalization, n (\%) } \\
\hline Sofosbuvir & $3(2.72)$ & $7(6.79)$ & 0.203 \\
\hline Interferon beta & $1(0.90)$ & $5(4.85)$ & 0.101 \\
\hline Ribavirin & 0 & $8(7.76)$ & 0.003 \\
\hline Corticosteroids & $11(10)$ & $24(23.30)$ & 0.01 \\
\hline IVIG & $5(4.54)$ & $13(12.62)$ & 0.047 \\
\hline Vitamin $\mathrm{C}$ & $10(9.09)$ & $28(27.18)$ & 0.001 \\
\hline Antibiotics, n (\%) & $36(32.72)$ & $62(60.19)$ & $<0.001$ \\
\hline NSAID (naproxen), n (\%) & $52(47.27)$ & $56(54.36)$ & 0.338 \\
\hline Diphenhydramine, n (\%) & $49(44.54)$ & $59(57.28)$ & 0.075 \\
\hline PPIs & $89(80.90)$ & $95(92.23)$ & 0.017 \\
\hline $\mathrm{H}_{2} \mathrm{RAs}$ & $12(10.90)$ & $5(4.85)$ & 0.131 \\
\hline UFH & $84(76.36)$ & $88(85.43)$ & 0.118 \\
\hline LMWH & $6(5.45)$ & $6(5.82)$ & 1.00 \\
\hline $\mathrm{ARBs}$ & $19(17.27)$ & $19(18.44)$ & 0.859 \\
\hline Statins & $17(15.45)$ & $27(26.21)$ & 0.063 \\
\hline ACEIs & $3(2.72)$ & $4(3.88)$ & 0.714 \\
\hline
\end{tabular}

IMV: invasive mechanical ventilation, NSAID: non-steroidal anti-inflammatory drug, $\mathrm{H}_{2} \mathrm{RA}: \mathrm{H}_{2}$ receptor antagonists, $\mathrm{PPI}$ : proton pump inhibitor, UFH: Unfractionated heparin, LMWH: Low molecular weight heparin, ARB: Angiotensin $\Pi$ Receptor Blocker, ACEI: angiotensin converting enzyme inhibitor 
Table 4 Efficacy and safety outcomes

\begin{tabular}{|c|c|c|c|}
\hline Parameter & Patients with moderate disease $(\mathrm{N}=110)$ & Patients with severe disease $(\mathrm{N}=103)$ & $\mathrm{p}$ value \\
\hline \multicolumn{4}{|l|}{ Efficacy outcomes } \\
\hline Discharge rate at day $7, \mathrm{n}(\%)$ & $85(77.27)$ & $51(49.51)$ & $<0.001$ \\
\hline Discharge rate at day $14, \mathrm{n}(\%)$ & $100(90.90)$ & $65(63.10)$ & $<0.001$ \\
\hline Discharge rate at day $28, \mathrm{n}(\%)$ & 104(94.54) & $72(69.90)$ & $<0.001$ \\
\hline 28-day mortality, n (\%) & $6(5.45)$ & $29(28.15)$ & $<0.001$ \\
\hline 56-day mortality, n (\%) & $7(6.36)$ & $33(32.03)$ & $<0.001$ \\
\hline $\begin{array}{l}\text { Duration of hospital stay, Mean } \pm \text { SD } \\
\text { (days) }\end{array}$ & $5 \pm 4$ & $8 \pm 6$ & $<0.001$ \\
\hline $\begin{array}{l}\text { Duration of ICU stay, Mean } \pm \text { SD } \\
\text { (days) }\end{array}$ & $6 \pm 5$ & $8 \pm 6$ & 0.191 \\
\hline Required ICU care, $\mathrm{n}(\%)$ & $20(18.18)$ & $39(37.86)$ & 0.002 \\
\hline Required IMV, n (\%) & $8(7.27)$ & $29(28.15)$ & $<0.001$ \\
\hline \multicolumn{4}{|l|}{ Safety outcomes } \\
\hline GI adverse effects & $14(12.72)$ & $22(21.35)$ & 0.103 \\
\hline ARDS & $20(11.36)$ & $35(33.98)$ & 0.012 \\
\hline AKI & $8(7.27)$ & $25(24.27)$ & 0.001 \\
\hline AHI & $6(5.45)$ & $16(15.53)$ & 0.023 \\
\hline ACI & $18(16.36)$ & $23(22.33)$ & 0.300 \\
\hline
\end{tabular}

IMV: invasive mechanical ventilation, AKI: acute kidney injury, AHI: acute hepatic injury, ARDS: acute respiratory distress syndrome, ACI: acute cardiac injury, GI: gastrointestinal

In this study, treatment with medications that were recommended in the national treatment protocol significantly improved discharge rates at days 7, 14 and 28 and reduced 28 - day mortality, need for admission in ICU and length of hospital stay in patients with moderate COVID-19 in comparison with patients with severe disease. Furthermore, patients with
Fig. 1 Kaplan-Meier cumulative survival plot

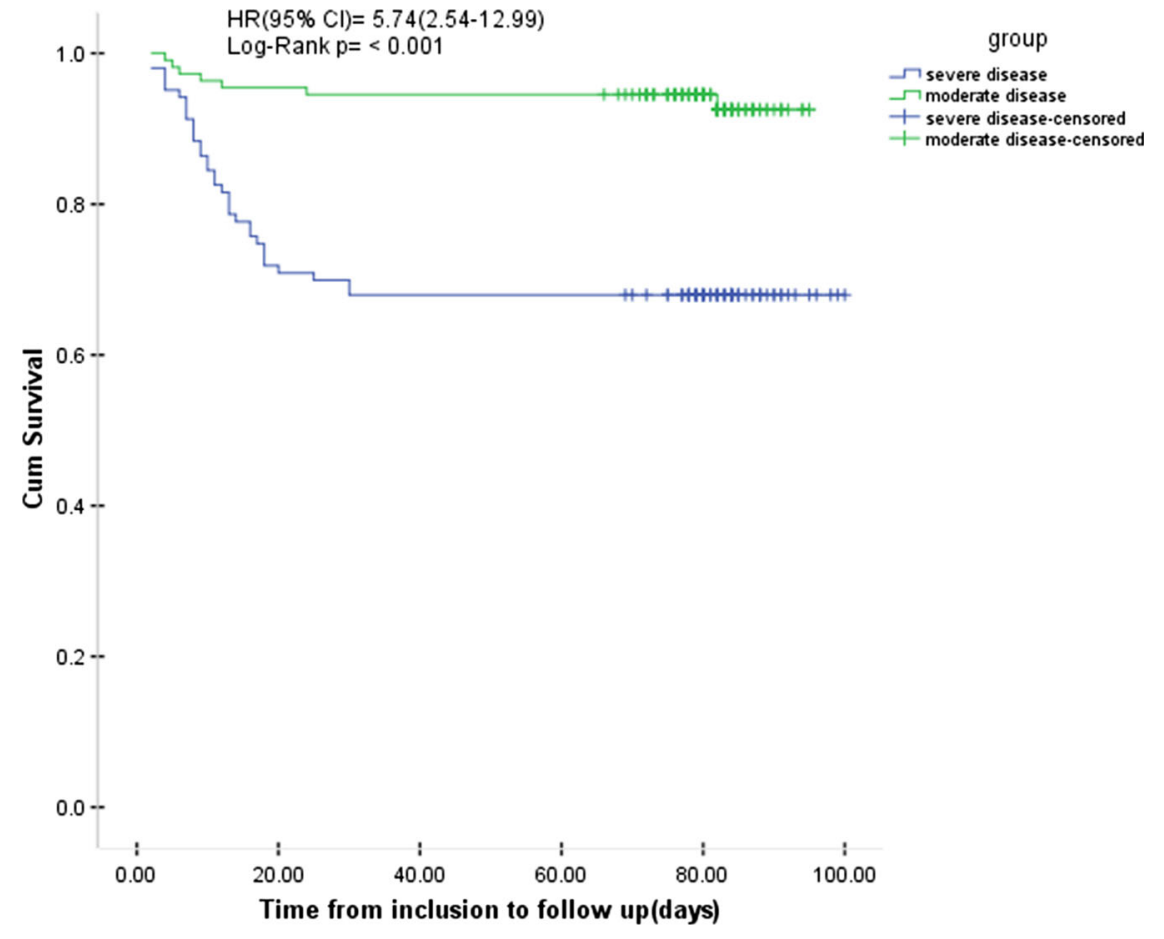

No. at risk

Moderate group 110

Severe group 103

104

103

$\begin{array}{ll}51 & 0 \\ 44 & 0\end{array}$ 
moderate disease experienced less serious adverse events and complications than patients with severe disease.

The demographic features, baseline diseases, drug history, symptoms at the time of hospital admission, time from symptoms' onset to hospital admission, initial vital signs and laboratory data were not statistically different between groups. Compared with patients with $\mathrm{SpO} 2<90 \%$, those with $\mathrm{SpO} 2 \geq 90 \%$ experienced more benefits following treatment with hydroxychloroquine plus atazanavir/ritonavir regimen. This finding will be important in management of patients with COVID-19 particularly in countries where this regimen is still in their protocols. This change in practice can have following benefits. First, the probability of drug shortage will decrease in future and drugs will be saved for main indications. Second, patients with severe disease are more prone to developing serious adverse effects such as cardiac side effects. So the selection of safe drug regimens is crucial. Third benefit of this change is prevention of drug interactions.

Although supportive cares are the cornerstones of management of patients with moderate COVID-19 in outpatient setting, according to the disease severity, further interventions may be considered for the hospitalized patients. According to the National Institutes Health (NIH) guideline [12], patients with lower respiratory tract involvement and $\mathrm{SpO} 2 \geq 94 \%$ in ambient air are in category of moderate disease while based on the WHO definition [6], patients with moderate disease have $\mathrm{SpO} 2 \geq 90 \%$. In most studies and large clinical trials, patients with SPO2 90-94\% were defined as severe while these patients were in moderate group in our study [13-15]. All patients needed supplemental oxygen in our study and their management was not possible at home. On the other hand, patients without requirement of supplemental oxygen were not admitted owing to limitations in number of hospital beds. Patients with low oxygen saturation are at risk for developing of cytokine release syndrome. Therefore, initiation of antivirals as soon as possible can decrease the virus replication and subsequent complications. According to the RECOVERY trial [16], NIH [12] and IDSA [17], a corticosteroid is recommended for patients requiring oxygen supplementation.

Hypertension, diabetes mellitus and cardiovascular diseases other than hypertension were in order the most common baseline diseases in the patients. This is same as Chinese investigations. However, hypertension, cardiovascular diseases, renal diseases and diabetes mellitus in order were common comorbidities in an American population [18, 19]. An interesting finding in this research is the partially high prevalence of hypothyroidism in approximately $10 \%$ of cases.

Dyspnea, cough and fever were the most common symptoms among the patients. The findings are similar to the results of other studies regarding fever and cough $[19,20]$ but dyspnea was marked as the most common symptom in our patients and Cummings et al. study [21]. The difference may be related to the admission protocol of our hospital. Patients who required respiratory supports had higher priority of the hospital admission. Furthermore, dyspnea is a subjective symptom and it cannot be precisely described like cough or fever. Fever was less common in our patients which may be due to use of analgesic and antipyretic at home.

The overall mortality on day 28 of inclusion in our patients was $16.43 \%$. This value was $86.49 \%$ in intubated patients. The mortality rate of COVID-19 is dependent on the severity of the disease and the site of patients' care. Moreover, in most studies the mortality rate was underestimated owing to short follow up period. In Zhang et al. study the overall mortality was 5.4\% while $75.6 \%$ of their patient were still in hospital [18]. In another study in which outcomes of 1590 patients were reported, the mortality rate was about $3 \%$ while only $3.1 \%$ of the patients needed IMV. On the other hand, the risk stratification of the patients was different [22]. In Zhou et al. study, the overall mortality and intubation rates were $28 \%$ and $17 \%$, respectively. Despite the similarity in the proportions of the intubated patients, the mortality rate was higher than in our study. Although the exact definition of disease severity was not clearly reported, $63 \%$ of their patients had severe to critical disease. The overall mortality rate of the study was similar to mortality rate of patients with severe disease in our study [23].

The most frequent side effect of the treatment protocol was gastrointestinal (nausea, vomiting, abdominal discomfort and diarrhea) like other studies [13, 24]. All were detected following initiation of the treatment. Thirty-five patients mainly in the severe group received corticosteroid which was started in the late phase of disease ( $>10$ days after the time of hospital admission). Patients received $125 \mathrm{mg}$ methyl prednisolone daily for 3 days. Most of these patients were in ICU and also experienced ARDS at that time. The effect of corticosteroid administration on mortality must be interpreted with caution as fewer patients in the moderate group received corticosteroid. Furthermore, a substantial number of patients in the severe group developed ARDS and multi-organ failure. However, the use of corticosteroid may non-significantly increase the risk of mortality [25]. Moreover, without reduction in mortality rate, these medications can increase duration of hospital stay [26]. The effects on mortality and outcomes can be generalized to IVIG and vitamin C in our study. IVIG not only did not show the survival benefits in a multicenter retrospective study but also increased total duration of the symptoms and hospital stay [27].

ARDS was the most serious complication that occurred in high number of patients compared with other complications. The incidence rate of ARDS was reported between 17 and $30 \%[23,28]$.

Extra-pulmonary complications can also occur in patients with COVID-19. Renal involvement can happen through 
different mechanisms [29]. Hepatic injury is expected following direct invasion of the virus to hepatic cells, like that was described in SARS [30]. Higher rates of organs involvement i.e. $33 \%$ for liver and $22.5 \%$ for kidney were previously reported in COVID-19 patients [31]. Hospitalized patients, especially critically ill ones, were more prone to incidence of AKI [32]. AKI developed in $89.19 \%$ of the intubated patients similar to other studies. In the study of Argenziano et al. AKI was reported in $89.7 \%$ of intubated patients [33]. Moreover, in a study from New York $78 \%$ of patients admitted in ICU developed AKI. Of note, more than $93 \%$ of their patients were intubated [34].

Lagier et al. assessed the clinical outcomes of patients treated with the combination of hydroxychloroquine/ azithromycin and other regimens. The outcomes of their study included mortality rate, ICU admission rate, duration of hospitalization $\geq 10$ days and viral shedding. Two clinical outcomes of the study (mortality rate and ICU requirement) can be compared with our study. The case fatality rate was $0.9 \%$ that reached $1.1 \%$ in the follow up. The overall mortality rate of our patients treated with hydroxychloroquine in combination with atazanavir/ritonavir was $17.37 \%$. This value was $5.45 \%$ in patients with moderate disease. The main differences between two studies are the disease severity and clinical presentation of the patients. Eighty-two percent of the patients were treated in a day-care hospital and only $18 \%$ of the patients were hospitalized in the wards. However, all of our patients were admitted to hospital and received the supportive care and antiviral agents. On the other hand, only $1.8 \%$ of their patients needed admission in ICU. In our study, approximately $28 \%$ of the patients required the intensive cares [35]. Geleris et al. evaluated association between hydroxychloroquine use and intubation requirement or death in an observational study [36]. Intubation or death occurred in $32.3 \%$ of hydroxychloroquine users. The hazard ratio was 2.37 in crude analysis versus 1.04 in multivariable analysis. Finally, authors concluded that hydroxychloroquine did not increase or decrease the mortality rate. Evaluating the effect of hydroxychloroquine use on mortality was not possible in our study because of all patients receiving it.

Arshad et al. evaluated outcome of 2541 patients treated with hydroxyclroquine alone and in combination with azithromycin during a multicenter retrospective study. Hydroxyclroquine was administrated as $400 \mathrm{mg}$ BD on first day then $200 \mathrm{mg}$ BD for 4 days. The dose of azithromycin was $500 \mathrm{mg}$ daily on first day and then $250 \mathrm{mg}$ daily on days $2-5$. In-hospital mortality was considered as the primary outcome. The overall mortality rate was $18.1 \%$. This value was $13.5 \%$, $20.1 \%, 22.4$ and $26.4 \%$ in the patients who received hydroxyclroquine alone, hydroxyclroquine + azithromycin, azithromycin alone and none of these medications respectively [37]. Same as our study, of these patients $50 \%$ had $\mathrm{SpO}_{2}<$ $90 \%, 24.2 \%$ needed ICU admission and $17.6 \%$ were intubated. Furthermore, the overall in-hospital mortality rates were similar (18.1\% versus $17.3 \%)$. Nevertheless, the patients were different in terms of underlying diseases and receipt of second antiviral and immunomodulatory medications. Although this study was multicenter, the design was retrospective. Our study was single center but all patients were prospectively monitored during the hospital course and followed up after discharge.

One of the first studies reporting benefits of hydroxychloroquine in the treatment of patients with COVID-19 was the study of Gautret et al. Viral clearance at day 6 of inclusion was considered as primary outcome. Hydroxychloroquine alone and in combination with azithromycin reduced viral load and accelerated viral clearance. Due to small sample size, non-randomization and dropout of six patients from the analysis, their results should be interpreted with caution [38].

The second common drug in the patients' drug regimens was an antiretroviral. Cao et al. evaluated the efficacy of lopinavir/ritonavir in patients with severe COVID-19. The primary outcome of the study was the time to clinical improvement that was defined according to seven- category scale. Lopinavir/ritonavir did not make a difference in time to clinical improvement compared with the standard of care. Late initiation of the drug in majority of patients (the median time from onset of symptoms to randomization was 13 days) is a major concern in this study. In our study, the antiretroviral agent was initiated as soon as possible following admission. Although mortality rate of that study was similar to our study but there are important differences between them: 1) longer duration of follow up in our study 2) more patients in our study required IMV during the course of hospitalization 3) all recruited patients in our study needed oxygen support. Similar to our study, the most frequent side effect of lopinavir/ritonavir was GI adverse effects [13].

Following limitations should be considered before interpretation of our findings. First, the design of the study was observational. Second, some laboratory tests required for monitoring the treatment regimen were not repeated during the hospitalization course. Third, the cardiovascular side effects of hydroxychloroquine was not reported while they are important and prevalent according to recent studies. Forth major limitation of the study was the lack of repeated molecular tests and chest imaging during the hospitalization course or at the time of hospital discharge.

\section{Conclusions}

Our study did not support the use of hydroxychloroquine plus atazanavir/ritonavir in patients who had $\mathrm{SpO}_{2}<90 \%$ at the time of hospital admission. $\mathrm{SpO} 2$ was the only predictor of clinical outcomes (duration of hospital stay, discharge from 
the hospital and mortality) in patients treated with hydroxychloroquine plus atazanavir/ritonavir.

Acknowledgements Office of Vice- Chancellor for Research of Tehran University of Medical Sciences, Tehran, Iran supported this work. We would like to thank the nurses of Imam Khomeini Hospital Complex for their kind supports and also Ms. Ava Khalili for English proofreading the manuscript.

Author's contribution Hamid Rahmani: Data collection and preparation primary draft of the manuscript.

Effat Davoudi-Monfared: Data collection, help to draft manuscript.

Anahid Nourian: Data collection.

Morteza Nabiee: Data collection.

Setayesh Sadeghi: Data collection.

Hossein Khalili: Conceptualization, supervision, review and edit manuscript.

Ladan Abbasian: Clinical assessment of patients.

Fereshteh Ghiasvand: Clinical assessment of patients.

Arash Seifi: Clinical assessment of patients.

Malihe Hasannezhad: Clinical assessment of patients.

Sara Ghaderkhani: Clinical assessment of patients.

Mostafa Mohammadi: Clinical assessment of patients.

Mir Saeed Yekaninejad: Data analysis.

Funding information The authors did not receive support from any organization for the submitted work.

\section{Compliance with ethical standards}

Declaration of interest The authors have no conflicts of interest to declare that are relevant to the content of this article.

\section{References}

1. WHO. Novel coronavirus - China. 2020. Available at: https://www. who.int/emergencies/diseases/novel-coronavirus-2019. Accessed 19 Jan 2020.

2. Peeri NC, Shrestha N, Rahman MS, Zaki R, Tan Z, Bibi S, et al. The SARS, MERS and novel coronavirus (COVID-19) epidemics, the newest and biggest global health threats: what lessons have we learned? Int J Epidemiol. 2020; dyaa033. https://doi.org/10.1093/ ije/dyaa033.

3. Cucinotta D, Vanelli M. WHO Declares COVID-19 a Pandemic. Acta Biomed. 2020;91(1):157-60. https://doi.org/10.23750/abm. v91i1.9397.

4. Johns Hopkins Coronavirus Resource Center Home Page (https:// coronavirus.jhu.edu/map.html), Accessed 23 July 2020.

5. Phadke M, Saunik S. COVID-19 treatment by repurposing drugs until the vaccine is in sight. Drug Dev Res. 2020;81:541-3. https:// doi.org/10.1002/ddr.21666.

6. IMAI District Clinician Manual. Hospital care for adolescents and adults. Geneva: World Health Organization; 2020 (https://apps. who.int/iris/bitstream/handle/10665/77751/9789241548290 Vol2_eng.pdf?sequence=3, Accessed 13 May 2020).

7. Clinical management of severe acute respiratory infection when Novel coronavirus (nCoV) infection is suspected: interim guidance. World Health Organization. March 13, 2020. https://www.who.int/ docs/default-source/coronaviruse/clinical-management-of-novelcov.pd. Accessed 11 Jan 2020.

8. Pisani L, Roozeman JP, Simonis FD, Giangregorio A, van der Hoeven SM, et al. Risk stratification using $\mathrm{SpO} 2 / \mathrm{FiO} 2$ and PEEP at initial ARDS diagnosis and after $24 \mathrm{~h}$ in patients with moderate or severe ARDS. Ann Intensive Care. 2017;7(1):108. https://doi. org/10.1186/s13613-017-0327-9.

9. Khwaja A. KDIGO clinical practice guidelines for acute kidney injury. Nephron Clin Pract. 2012;120(4):c179-84. https://doi.org/ 10.1159/000339789.

10. Lescot T, Karvellas C, Beaussier M, Magder S. Acquired liver injury in the intensive care unit. Anesthesiology. 2012 Oct;117(4):898-904. https://doi.org/10.1097/ALN. 0b013e318266c6df.

11. Shi S, Qin M, Shen B, Cai Y, Liu T, Yang F, et al. Association of cardiac injury with mortality in hospitalized patients with COVID19 in Wuhan, China. JAMA Cardiol. 2020;25:2020. https://doi.org/ 10.1001/jamacardio.2020.0950.

12. COVID-19 Treatment Guidelines Panel. Coronavirus Disease 2019 (COVID-19) Treatment guidelines. National Institutes of Health. Available at https://www.covid19treatmentguidelines.nih.gov/. Accessed 8 Aug 2020.

13. Cao B, Wang Y, Wen D, Liu W, Wang J, Fan G, et al. A trial of Lopinavir-ritonavir in adults hospitalized with severe Covid-19. NEJM. 2020;382:1787-99. https://doi.org/10.1056/ NEJMoa2001282.

14. Wang Y, Zhang D, Du G, Du R, Zhao J, et al. Remdesivir in adults with severe COVID-19: a randomised, double-blind, placebo-controlled, multicentre trial. Lancet. 2020;395(10236):1569-78. https://doi.org/10.1016/S0140-6736(20)31022-9.

15. Goldman JD, Lye DCB, Hui DS, Marks KM, Bruno R, Montejano $\mathrm{R}$, et al. Remdesivir for 5 or 10 days in patients with severe Covid19. N Engl J Med. 2020. https://doi.org/10.1056/NEJMoa2015301.

16. Horby P, Lim WS, Emberson JR, Mafham M, Bell JL, et al. Dexamethasone in hospitalized patients with Covid-19 - preliminary report. N Engl J Med. 2020. https://doi.org/10.1056/ NEJMoa2021436.

17. Bhimraj A, Morgan RL, Shumaker AH, Lavergne V, Baden L, et al. Infectious Diseases Society of America Guidelines on the Treatment and Management of Patients with COVID-19. Clin Infect Dis. 2020; ciaa478. https://doi.org/10.1093/cid/ciaa478.

18. Zhang G, Hu C, Luo L, Fang F, Chen Y, Li J, et al. Clinical features and short-term outcomes of 221 patients with COVID-19 in Wuhan, China. J Clin Virol. 2020;127:104364. https://doi.org/10. 1016/j.jcv.2020.104364.

19. McMichael TM, Clark S, Pogosjans S, Kay M, Lewis L, Baer A. COVID-19 in a long-term care facility - King County, Washington, February 27-March 9, 2020. MMWR Morb Mortal Wkly Rep. 2020;69:339-42. https://doi.org/10.15585/mmwr. mm6912e1.

20. Wu J, Liu J, Zhao X, Liu C, Wang W, Wang D, et al. Clinical characteristics of imported cases of coronavirus disease 2019 (COVID-19) in Jiangsu Province: a multicenter descriptive study. Clin Infect Dis. 2020;71:706-12. https://doi.org/10.1093/cid/ ciaa199.

21. Cummings MJ, Baldwin MR, Abrams D, Jacobson SD, Meyer BJ, Balough EM, et al. Epidemiology, clinical course, and outcomes of critically ill adults with COVID-19 in New York City: a prospective cohort study. Lancet. 2020;395:1763-70. https://doi.org/10.1016/ S0140-6736(20)31189-2.

22. Guan WJ, Liang WH, Zhao Y, Liang HR, Chen ZS, Li YM, et al. Comorbidity and its impact on 1590 patients with COVID-19 in China: a nationwide analysis. Eur Respir J. 2020;55(5):2000547. https://doi.org/10.1183/13993003.00547-2020.

23. Zhou F, Yu T, Du R, Fan G, Liu Y, Liu Z, et al. Clinical course and risk factors for mortality of adult inpatients with COVID19 in Wuhan, China: a retrospective cohort study. Lancet. 2020;395(10229):1054-62. https://doi.org/10.1016/S01406736(20)30566-3. 
24. Srinivasa A, Tosounidou S, Gordon C. Increased incidence of gastrointestinal side effects in patients taking hydroxychloroquine: a brand-related issue? J Rheumatol. 2017;44(3):398-39398. https:// doi.org/10.3899/jrheum.161063.

25. Wang D, Wang J, Jiang Q, Yang J, Li J, Gao C, et al. No clear benefit to the use of corticosteroid as treatment in adult patients with coronavirus disease 2019: A retrospective cohort study. MedRxiv. https://doi.org/10.1101/2020.04.21.20066258.

26. Lu S, Zhou Q, Huang L, Shi Q, Zhao S, Wang Z, et al. Effectiveness and safety of glucocorticoids to treat COVID-19: a rapid review and meta-analysis. MedRxiv. https://doi.org/10.1101/ 2020.04.17.20064469.

27. Shao Z, Feng Z, Zhong L, Xie Q, Lei M, Liu Z, et al. Clinical efficacy of intravenous immunoglobulin therapy in critical patients with COVID-19: a multicenter retrospective cohort study. MedRxiv. https://doi.org/10.1101/2020.04.11.20061739.

28. Wan S, Xiang Y, Fang W, Zheng Y, Li B, Hu Y, et al. Clinical features and treatment of COVID-19 patients in Northeast Chongqing. J Med Virol. 2020;92:797-806. https://doi.org/10. 1002/jmv.25783.

29. Ronco C, Reis T. Kidney involvement in COVID-19 and rationale for extracorporeal therapies. Nat Rev Nephrol. 2020;16:308-10. https://doi.org/10.1038/s41581-020-0284-7.

30. Zhang C, Shi L, Wang F. Liver injury in COVID-19: management and challenges. Lancet Gastroenterol Hepatol. 2020;5:428-30. https://doi.org/10.1016/S2468-1253(20)30057-1.

31. Fu L, Fei J, Xiang H, Xiang Y, Tan Z, Li M, et al. Influence factors of death risk among COVID-19 patients in Wuhan, China: a hospital-based case-cohort study. medRxiv. 2020. https://doi.org/ 10.1101/2020.03.13.20035329.

32. Truche AS, Ragey SP, Souweine B, Bailly S, Zafrani L, Bouadma $\mathrm{L}$, et al. ICU survival and need of renal replacement therapy with respect to AKI duration in critically ill patients. Ann Intensive Care. 2018;8:127. https://doi.org/10.1186/s13613-018-0467-6.

33. Hirsch JS, Ng JH, Ross DW, Sharma P, Shah HH, Barnett RL, et al. Acute kidney injury in patients hospitalized with COVID-19. Kidney Int. 2020 May 16;98:209-18. https://doi.org/10.1016/j. kint.2020.05.006.

34. Argenziano MG, Bruce SL, Slater CL, Tiao JR, Baldwin MR, Barr $\mathrm{RG}$, et al. Characterization and clinical course of 1000 patients with coronavirus disease 2019 in New York: retrospective case series. BMJ. 2020. https://doi.org/10.1136/bmj.m1996.

35. Lagier JC, Million M, Gautret P, Colson P, Cortaredona S, GiraudGatineau A, et al. Outcomes of 3,737 COVID-19 patients treated with hydroxychloroquine/azithromycin and other regimens in Marseille, France: a retrospective analysis. Travel Med Infect Dis. 2020;36:101791. https://doi.org/10.1016/j.tmaid.2020.101791.

36. Geleris J, Sun Y, Platt J, Zucker J, Baldwin M, Hripcsak G, et al. Observational study of Hydroxychloroquine in hospitalized patients with Covid-19. N Engl J Med. 2020;382:2411-8. https:// doi.org/10.1056/NEJMoa2012410.

37. Arshad S, Kilgore P, Chaudhry ZS, Jacobsen G, Wang DD, Huitsing K, et al. Treatment with hydroxychloroquine, azithromycin, and combination in patients hospitalized with COVID-19. Int J Infect Dis. 2020;97:396-403. https://doi.org/10. 1016/j.ijid.2020.06.099.

38. Gautret P, Lagier JC, Parola P, Hoang VT, Meddeb L, Mailhe M, et al. Hydroxychloroquine and azithromycin as a treatment of COVID-19: results of an open-label non-randomized clinical trial. Int J Antimicrob Agents. 2020 Mar 20;56:105949. https://doi.org/ 10.1016/j.ijantimicag.2020.105949.

Publisher's note Springer Nature remains neutral with regard to jurisdictional claims in published maps and institutional affiliations. 